\title{
USING VIRTUAL LABORATORY ENVIRONMENT FOR SCIENCE EDUCATION IN DIFFERENT EDUCATIONAL SETTINGS
}

\author{
Athanasios Sypsas, Evgenia Paxinou, Dimitris Kalles, Hellenic Open University, Greece
}

\section{Abstract}

\begin{abstract}
Although hands-on laboratory experiments have been traditionally used in education, virtual laboratories have become popular in science courses due to their specific features. In this study, we asked for the students' opinion on using a 3D desktop-based virtual reality biology lab in two different educational settings, upper secondary education (Lyceum) and University. Our findings indicate that both Lyceum and University students found the use of the virtual laboratory interesting, when learning and practicing on the use of an optical microscope. According to the students' answers in a specially designed Likertstyle questionnaire, this virtual reality-based learning experience was rather satisfactory, helped them easily understand the new topic of microscopy and filled them with confidence regarding their capability to conduct the specific microscopy experiment in a real biology lab. These results, combined with similar findings from other studies, suggest that virtual environments are viewed favourably by students and could be used supplementary to traditional teaching methods applied in hands-on laboratories in different educational settings.
\end{abstract}

\section{Introduction}

The rapid advances in ICT and the ever-increasing Internet access use provide new educational tools both for educators and students (de Jong \& van Joolingen, 1998). The access to information is increased and the collaboration between educators and students is enhanced (Smetana \& Bell, 2012) contributing significantly to a better understanding of the different scientific concepts (Allen Moore \& Russell Smith, 2012).

Simulations in modern ICT educational applications, are often used in science education as they can support constructive learning, while they are very effective in dynamically engaging learners in the learning process (Makransky, Thisgaard, \& Gadegaard, 2016). In the education field, simulations provide an educational environment for experiments, helping learners to comprehend and adopt real laboratory practices and skills (de Jong \& van Joolingen, 1998). However, instructors in the Science, Technology, and Engineering field are sometimes reluctant to adopt the new technological approaches, particularly in 
distance education, since hands-on laboratory sessions are required (Potkonjak et al., 2016) and have always been the key pillar of science education (Hofstein \& Lunetta, 2004). In order to achieve their educational purposes, laboratories must be fully equipped, concerning materials, facilities and training staff. When these requirements cannot be completely met, virtual laboratories (VLs) may offer a supplementary but essential solution, especially in distance education and when epidemiological situations (i.e., COVID-19 era) prevent students from on-campus laboratories. Having also in mind that positive attitudes toward science tend to decline with age, from primary through the secondary school years (Marginson et al., 2013), virtual environments can help students not to be deprived from their school labs, an environment that contributes to occurrence of meaningful learning. VLs are based on simulations of models used to abstractly describe a physical laboratory and the experiments taking place therein (Rossiter, 2016). Thus, while users perform their experiments in the VL, they get familiar with the laboratory environment and, consequently, can more actively participate in the educational process. Through virtual experimentation, learners familiarize themselves and become active learners (Paxinou et al., 2020a; 2020b), because decision-taking and learning by doing are promoted, when interacting with virtual environments (Martín-Gutiérrez et al., 2017). Furthermore, the use of technology-enhanced simulation leads to higher educational outcomes, compared to traditional educational methods (Paxinou et al., 2020a; 2020b), even if the target groups are learners that bring a zero to minimum prior knowledge on science topic. The vital benefits of VLs usage are identified in many studies, in various science domains (Heradio et al., 2016).

VLs are used in different educational settings as effective supplementary educational tool. However, the majority of applications are developed for the post-secondary educational settings, since computer laboratories needed for VLs are better organized and maintained at these settings. Additionally, post-secondary education students are familiar with the educational and ICT skills needed for experimentation in VL environment. Consequently, the most demanding applications of VLs are implemented in post-secondary education settings (Sypsas \& Kalles, 2018).

The present study aims to investigate the students' opinion from different educational setting on using a 3D desktop-based virtual reality biology lab, called Onlabs, to be trained on the operation of a photonic microscope. In our research two target groups, a class from the upper secondary education (Lyceum) and a class from the higher education followed the same virtual reality-oriented teaching method regarding the microscopy experiment. Finally, the two groups expressed their opinion on satisfaction, interest, confidence, understanding and cognitive load items using a 5-point Likert scale ( $1=$ Strongly Disagree, $5=$ Strongly Agree), evaluating this way, their learning experience. Our study pointed out 
that the group of young students in the secondary education had similar attitude towards the usefulness and the effectiveness of embedding a virtual lab in the learning procedure of a science course, with the students in higher education.

\section{The Participants and the Educational Materials}

\section{The Participants}

The sample consisted of 47 students, 23 undergraduate students from the Department of Primary Education at the University of Patras in Greece, and 24 upper secondary education (Lyceum) students from the city of Preveza, also in Greece. The undergraduate students were enrolled in the Computers and Education course, a course where students are primarily practicing in the computer use, are informed about the new educational software for primary and secondary education and are educated on technology-assisted teaching and learning. The Lyceum students were enrolled in science course, a course where, among other tasks, they are practicing in Chemistry and Biology experiments. These two totally different groups were selected with the assumption that they both represent a novice audience that brings a zero to minimum prior knowledge on the operation of a photonic microscope.

\section{The Virtual Reality Tool}

The virtual laboratory environment used in the present study is the Onlabs software (https://sites.google.com/site/onlabseap/). It is developed by an interdisciplinary team at Hellenic Open University (HOU), a distance education institution that is mastering the distance learning education. HOU has always been trying to introduce in the learning procedure new ways to communicate laboratory skills to the distance learning students. Recently, it was the students' demand to use a software that would help them remotely gain the basic experimental skills before appearing to the university premises. The virtual laboratory environment is depicted in Figure 1.

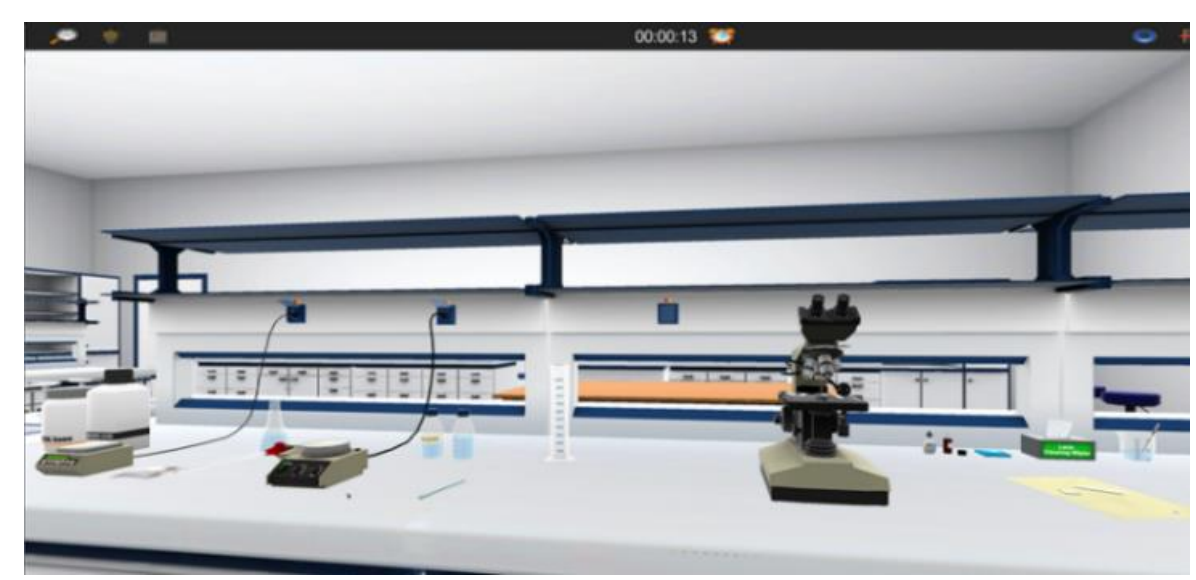

Figure 1. A screenshot from the virtual environment of Onlabs 


\section{The Likert-Style Questionnaire}

One of the most important roles, an educational application like Onlabs, must achieve is to maximize motivation. Motivation according to Keller (1983) is the goals you set, the efforts you spend to achieve them and your persistence trying to achieve them. The questionnaire used in this survey was based mostly on the Keller' work and especially on his ARCS Model. This model describes the students' motivation to learn in terms of four characteristics: Attention, Relevance, Confidence and Satisfaction. In our inquiry the Attention variable was replaced by the Interest variable, we omitted the Relevance variable and we added Understanding and Cognitive Load components. The current study tries to examine students' motivational response to VR technology and to better understand the reasons for this students' preference.

\section{Methodology}

The process of our study didn't harm or put the participants in a position of discomfort. The students were volunteers, taking part in the process of their own free will. They were given information on the methodology and the purpose of the research and they filled in the questionnaire by using as ID, a number, randomly selected, protecting this way their anonymity. Both undergraduate and secondary education students followed, the same teaching method presented in Table 1 . The only difference in the followed procedure was in step 3, where the undergraduate students interacted with Onlabs and practice on the microscopy experiment in the premises of their Institution, whereas the Lyceum students interacted with Onlabs at home.

Table 1: $\quad$ Steps in the teaching scenario for undergraduate and secondary education students

\begin{tabular}{|c|c|}
\hline Step/No & The Activities \\
\hline 1 & $\begin{array}{l}\text { All students attended an hour face-to-face tutorial. The tutor used PowerPoint slides to } \\
\text { introduce the principles of microscopy. The different parts of a photonic microscope, as } \\
\text { well as their specific function, were also presented }\end{array}$ \\
\hline 2 & $\begin{array}{l}\text { All participants entered the Computer Lab and the tutor performed a complete } \\
\text { microscopy procedure in Onlabs environment }\end{array}$ \\
\hline 3 & $\begin{array}{ll}\text { (a) The undergraduate students used their } & \text { (b) The Lyceum students went home, used } \\
\text { own PC in the Computer Lab and } & \text { their home PC and performed the } \\
\text { performed the microscopy experiment } & \text { microscopy experiment once again, in } \\
\text { once again, in Onlabs environment } & \text { Onlabs environment }\end{array}$ \\
\hline 4 & $\begin{array}{l}\text { All students filled in the Likert style questionnaire in order to express their opinion on } \\
\text { the specific learning experience, and handle it to the tutor }\end{array}$ \\
\hline
\end{tabular}

\section{Results}

The SPSS 26 statistical analysis program was used to analyse the data. In order to compare means of the answers for the two groups of students, the independent samples t-test was used. Additionally, observation data and also some discussion with all students was taken 
into consideration to support the quantitative data. Table 2 presents the five questions of the questionnaire that aim at evaluating the students' interest in Onlabs.

Table 2: The interest questions

\begin{tabular}{ll}
\hline Question ID & The Question \\
\hline I1 & This educational method is not at all boring \\
I2 & This educational method has some points that stimulate my curiosity \\
I3 & $\begin{array}{l}\text { The quality of the graphics, illustrations, etc., helped keep my attention on the } \\
\text { lesson }\end{array}$ \\
I4 & $\begin{array}{l}\text { During the course I never felt irritated, although lots of new topics were } \\
\text { introduced }\end{array}$ \\
I5 & I would choose this educational method again for all my experimental exercises \\
\hline
\end{tabular}

Figure 2 presents the percentages of the students' answers in the questionnaire, regarding the interest questions (I1, I2, I3, I4 and I5), based on the 5-point Likert scale ( $1=$ Strongly Disagree, 5 = Strongly Agree).

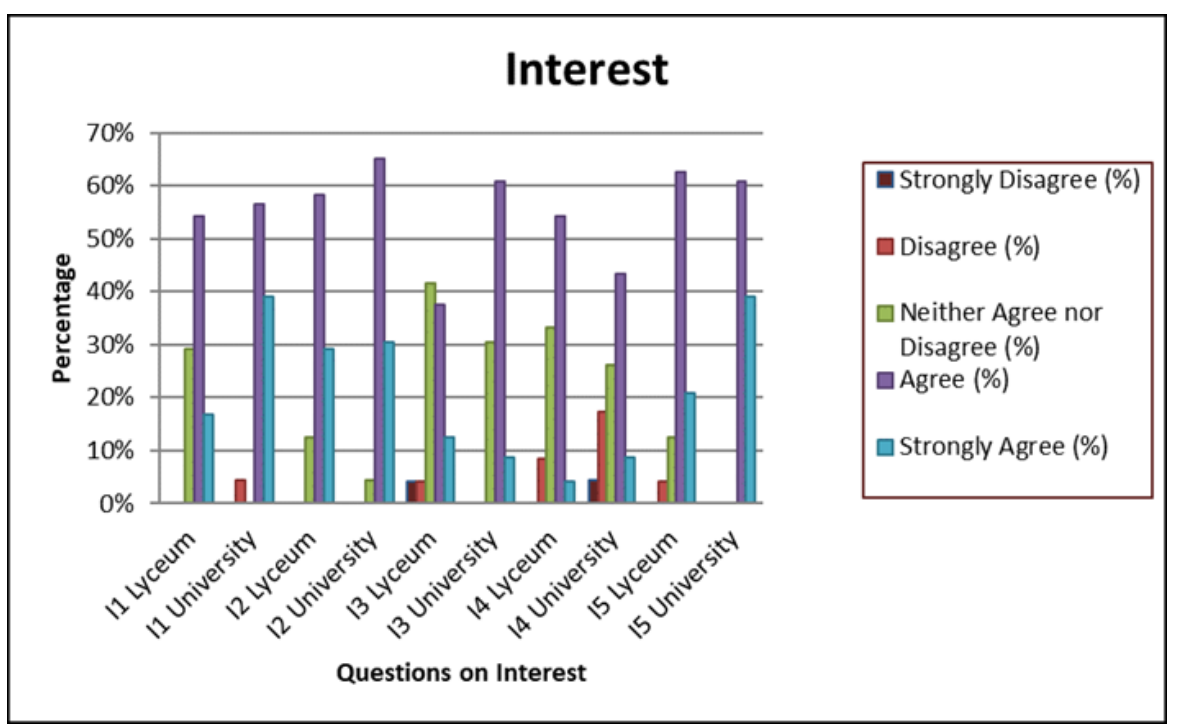

Figure 2. Percentages of the students' answers regarding the Interest questions

The visualization of the students' answers indicates that Lyceum and University students are almost equally interested in Onlabs as a new educational application. Table 3 demonstrates the rest of the question in our questionnaire were the Understanding (U) the Confidence (C), the Cognitive Load (CL) and the Satisfaction (S), after the students' interaction with Onlabs, is evaluated. 
Sypsas, A., Paxinou, E., \& Kalles, D.

Using Virtual Laboratory Environment for Science Education in Different Educational Settings

Table 3: The Understanding, Confidence, Cognitive Load and Satisfaction questions

\begin{tabular}{ll}
\hline Question ID & The Question \\
\hline U1 & $\begin{array}{l}\text { This educational method helped me understand the microscopy procedure } \\
\text { After following this educational method, I felt confident that I will do well in this } \\
\text { course } \\
\text { I believe that this educational method will help me use the microscope in the } \\
\text { biology }\end{array}$ \\
CL1 & $\begin{array}{l}\text { All steps in the microscopy procedure seemed easy to me } \\
\text { This educational method helped me understand microscopy much better than } \\
\text { my }\end{array}$ \\
m1 & I was really satisfied following this educational method
\end{tabular}

The percentages of the students' answers in Understanding, Confidence, Cognitive Load and Satisfaction questions, based on the 5-point Likert scale $(1=$ Strongly Disagree, $5=$ Strongly Agree) are presented in Figure 3. The answers indicate that both Lyceum and University students felt confident that will do well in their laboratory courses. Moreover, students stated that Onlabs helped them understand the microscoping procedure and offered them satisfaction during its use. The two groups had almost identical averages concerning the scales and the questions. First, on the scale of Interest, Lyceum students' responses were $(\mathrm{M}=3.82, \mathrm{SD}=.53)$ and University's $(\mathrm{M}=4.02, \mathrm{SD}=.47)$. This indicates more than half of the Lyceum (70\%) and University (82.5\%) students agreed or strongly agreed that Onlabs stimulated their curiosity and kept their attention on the lesson. Second, on the question of how Onlabs helped them understand the microscopy procedure, the means were $(\mathrm{M}=4.00, \mathrm{SD}=.72)$ for Lyceum and $(\mathrm{M}=4.30, \mathrm{SD}=.47)$ for University students. This indicates that $84 \%$ of Lyceum students and all (100\%) University students agree or strongly agree that Onlabs helped them towards comprehending the microscoping procedure. Regarding the confidence scale, Lyceum $(\mathrm{M}=4.38, \mathrm{SD}=.58)$ and University students $(\mathrm{M}=4.22, \mathrm{SD}=.52)$ had almost identical attitude. Conversely, concerning cognitive load, means for Lyceum were $(\mathrm{M}=3.94, \mathrm{SD}=.54)$ and for University $(\mathrm{M}=3.91$, $\mathrm{SD}=.42)$, indicating that $(73 \%)$ of Lyceum and $(73.9 \%)$ of University students felt that the educational procedure based on Onlabs was well organized and helped them understand all the new principles. Finally, on satisfaction question, students' responses were $(\mathrm{M}=3.92, \mathrm{SD}=.65)$ for Lyceum and $(\mathrm{M}=3.87, \mathrm{SD}=.69)$ for University. Approximately (83\%) of Lyceum and (78\%) of University students regarded that Onlabs educational approach offered them satisfaction. 


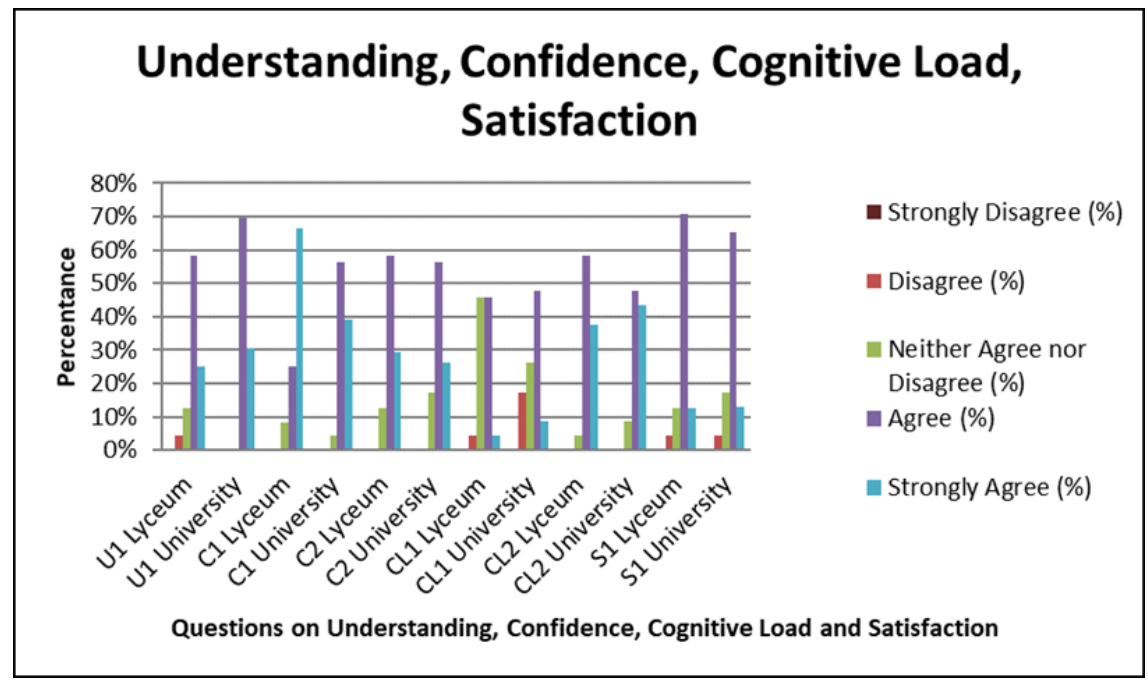

Figure 3. Percentages of the students' answers regarding Understanding, Confidence, Cognitive Load and Satisfaction questions

The results of independent samples t-test for the above means are presented in Table 4.

Table 4: $\quad$ t-test results

\begin{tabular}{lllll}
\hline Scale/ Question & $\mathrm{t}$-value & $\mathrm{p}$-value & $\mathrm{df}$ & Result \\
\hline Interest & 1.37 & .178 & 45 & $\begin{array}{l}\text { This difference is considered to be not } \\
\text { statistically significant }\end{array}$ \\
Understanding & 1.70 & .095 & 45 & $\begin{array}{l}\text { This difference is considered to be not } \\
\text { statistically significant }\end{array}$ \\
Confidence & 0.99 & .330 & 45 & $\begin{array}{l}\text { This difference is considered to be not } \\
\text { statistically significant }\end{array}$ \\
Cognitive Load & 0.17 & .863 & 45 & $\begin{array}{l}\text { This difference is considered to be not } \\
\text { statistically significant } \\
\text { This difference is considered to be not } \\
\text { Statistically significant }\end{array}$ \\
\hline
\end{tabular}

As results indicate, there is no significant difference between Lyceum and University students for all scales and questions of the questionnaire. Both Lyceum and University students agreed that Onlabs based educational approach irritated their interest, helped them concentrate on the lesson, understand the microscoping experiment, and all the new principles.

\section{Discussion}

In the present study, we investigated the results of the use of the Onlabs virtual laboratory environment for Lyceum and University students, concerning their interest, understanding, confidence, cognitive load and satisfaction during the specific educational approach. The results showed that the students were interested in the specific innovative approach, as the virtual environment encouraged their involvement. This finding is in consistence with the study of Parong and Mayer (2018), where is stated that Virtual Reality environments as a new popular technology is more motivating than conventional media. 
Similarly, in other studies, the use of animations and VLs has been reported to challenge students, increase their intrinsic motivation to study and their interest towards lessons (Kollöffel \& de Jong, 2013). Moreover, the use of Onlabs both for Lyceum and University students contributed in the increase of microscoping procedure understanding, as they played an active role during the experimentation. These findings are comparable with other studies, where students were using interactive computer animations with different scenarios and parameters, which helped them acquiring the concepts and making sense of them and also increase their knowledge (Akpınar, 2014; Polly et al., 2014). As far as cognitive load is concerned, students both in Lyceum and University agreed that Onlabs led them to positive cognitive outcomes. The same results were reported in other studies (Bonde et al., 2014). However, the combined use of hands-on and virtual experimentation could have led to higher cognitive learning outcomes and have helped students to learn better than doing either a physical or virtual experiment alone (Parong \& Mayer, 2018). Data from the present study indicated that the students felt confident and satisfied when using virtual laboratory as part of the educational procedure, since they found Onlabs environment easy to use and stimulating. These findings are consistent with previous research that presents the virtual environments as tools that contribute to students' confidence and self-efficacy increase (Makransky et al., 2016).

\section{Limitations and Future Research}

Although our results presented that Undergraduate and Lyceum students showed a similar positive attitude towards Onlabs, it must be kept in mind that this study was carried out with a small sample of participants. Therefore, although our research gave us some promising hints about the potential educational character of Onlabs, we must emphasize the necessity for further investigations of the effects of VR on more numerous groups of students. Furthermore, since the main aim of this project was to find out the students' opinion about Onlabs, a questionnaire with more questions should be designed. By designing a brief questionnaire, our intention was to get sincere answers by not tiring the respondents.

\section{Conclusion}

This study revealed that both Lyceum and University students found interesting the use of the Onlabs VL, when studying and practicing on focusing on a specimen by using an optical microscope. The students were interested in this learning experience and claimed that they have easily understood the new topic of microscopy, a topic with a quite high intrinsic load. After their interaction with the virtual environment, the students were satisfied and were feeling very confident to repeat the real microscopy experiment, this time in a real biology lab. The students' answers in the given questionnaire showed that 
both Lyceum and University students had similar attitude towards the virtual reality lab, as the differences in their responses were considered to be not statistically significant.

\section{References}

Akpinar, E. (2014). The use of interactive computer animations based on POE as a presentation tool in primary science teaching. Journal of Science Education and Technology, 23(4), 527-537. https://doi.org/10.1007/s10956-013-9482-4

Allen Moore, W., \& Russell Smith, A. (2012). Effects of video podcasting on psychomotor and cognitive performance, attitudes and study behaviour of student physical therapists. Innovations in Education and Teaching International, 49(4), 401-414. https://doi.org/10.1080/14703297.2012.728876

Bonde, M. T., Makransky, G., Wandall, J., Larsen, M. V, Morsing, M., Jarmer, H., \& Sommer, M. O. A. (2014). Improving biotech education through gamified laboratory simulations. Nature Biotechnology, 32(7), 694-697. https://doi.org/10.1038/nbt.2955

Heradio, R., de la Torre, L., Galan, D., Cabrerizo, F. J., Herrera-Viedma, E., \& Dormido, S. (2016). Virtual and remote labs in education: A bibliometric analysis. Computers and Education, 98, 14-38. https://doi.org/10.1016/j.compedu.2016.03.010

Hofstein, A., \& Lunetta, V. N. (2004). The Laboratory in Science Education: Foundations for the Twenty-First Century. Science Education, 88(1), 28-54. https://doi.org/10.1002/sce.10106

de Jong, T., \& van Joolingen, W. R. (1998). Scientific Discovery Learning with Computer Simulations of Conceptual Domains. Review of Educational Research, 68(2), 179-201. https://doi.org/10.3102/00346543068002179

Keller, J. M. (1983). Development and use of the ARCS model of motivational design. Enschede, Netherlands: Technische Hogeschool Twente.

Kollöffel, B., \& de Jong, T. A. J. M. (2013). Conceptual understanding of electrical circuits in secondary vocational engineering education: Combining traditional instruction with inquiry learning in a virtual lab. Journal of Engineering Education, 102(3), 375-393. https://doi.org/10.1002/jee.20022

Makransky, G., Bonde, M. T., Wulff, J. S. G., Wandall, J., Hood, M., Creed, P. A., \& Nørremølle, A. (2016). Simulation based virtual learning environment in medical genetics counseling: an example of bridging the gap between theory and practice in medical education. BMC Medical Education, 16(1), 98. https://doi.org/10.1186/s12909016-0620-6 
Makransky, G., Thisgaard, M. W., \& Gadegaard, H. (2016). Virtual simulations as preparation for lab exercises: Assessing learning of key laboratory skills in microbiology and improvement of essential non-cognitive skills. PLoS ONE, 11(6), 1-11. https://doi.org/10.1371/journal.pone.0155895

Marginson, S., Tytler, R., Freeman, B., \& Roberts, K. (2013). STEM: country comparisons: international comparisons of science, technology, engineering and mathematics (STEM) education. Melbourne, Vic.: Australian Council of Learned Academie. https://doi.org/10.1093/0195300912.003.0009

Martín-Gutiérrez, J., Mora, C. E., Añorbe-Díaz, B., \& González-Marrero, A. (2017). Virtual technologies trends in education. Eurasia Journal of Mathematics, Science and Technology Education, 13(2), 469-486. https://doi.org/10.12973/eurasia.2017.00626a

Parong, J., \& Mayer, R. E. (2018). Learning science in immersive virtual reality. Journal of Educational Psychology, 110(6), 785-797. https://doi.org/10.1037/edu0000241

Paxinou, E., Georgiou, M., Kakkos, V., Kalles, D., \& Galani, L. (2020a). Achieving educational goals in microscopy education by adopting virtual reality labs on top of face-to-face tutorials. Research in Science \& Technological Education, 1-20. https://doi.org/10.1080/02635143.2020.1790513

Paxinou, E., Panagiotakopoulos, C. T., Karatrantou, A., Kalles, D., \& Sgourou, A. (2020b). Implementation and Evaluation of a Three-Dimensional Virtual Reality Biology Lab versus Conventional Didactic Practices in Lab Experimenting with the Photonic Microscope. Biochemistry and Molecular Biology Education, 48(1), 21-27. https://doi.org/10.1002/bmb.21307

Polly, P., Marcus, N., Maguire, D., Belinson, Z., \& Velan, G. M. (2014). Evaluation of an adaptive virtual laboratory environment using Western Blotting for diagnosis of disease. BMC Medical Education, 14(1). https://doi.org/10.1186/1472-6920-14-222

Potkonjak, V., Gardner, M., Callaghan, V., Mattila, P., Guetl, C., Petrović, V. M., \& Jovanović, K. (2016). Virtual laboratories for education in science, technology, and engineering: A review. Computers and Education, 95, 309-327. https://doi.org/10.1016/j.compedu.2016.02.002

Rossiter, J. A. (2016). Low production cost virtual modelling and control laboratories for chemical engineering students. IFAC-PapersOnLine, 49(6), 230-235. https://doi.org/10.1016/J.IFACOL.2016.07.182 
Smetana, L. K., \& Bell, R. L. (2012). Computer Simulations to Support Science Instruction and Learning: A critical review of the literature Computer Simulations to Support Science Instruction and Learning: A critical review of the literature. International Journal of Science Education, 34(9), 1337-1370.

https://doi.org/10.1080/09500693.2011.605182

Sypsas, A., \& Kalles, D. (2018). Virtual laboratories in biology, biotechnology and chemistry education: a literature review. In K. Nikitas \& M. Basilis (Eds.), Proceedings of the $22^{\text {nd }}$ Pan-Hellenic Conference on Informatics (pp. 70-75). Athens, Greece: ACM New York, NY, USA C 2018. https://doi.org/10.1145/3291533.3291560 